\title{
Duodenal perforation due to an ERCP stent migration after liver transplantation
}

\author{
Burak Mahmut Kılcı, (1) Sertaç Usta, (1) Burak Işık, (1) Sezai Yılmaz \\ Department of General Surgery, Inonu University, Malatya, Turkey
}

\begin{abstract}
Biliary tract complications are one of the most common complications, after liver transplantation. Endoscopic retrograde cholangiopancreatography (ERCP) is a frequently performed diagnostic and therapeutic procedure for those complications. Stent dislocation after ERCP procedure is a very rare complication. There are only case reports, about the perforation complications due to stent migration in the literature. Therefore, there is not enough data about the incidence of this complication. Here, we present a case who had ERCP procedure due to biliary tract stricture after liver transplantation. The patient admitted with an abdominal pain and intra-abdominal free liquid was detected on computed tomography scan. The patient was urgently operated and primary repair of the duodenal perforation was performed.
\end{abstract}

Keywords: Endoscopic retrograde cholangiopancreatography stent dislocation, intestinal perforation, liver transplantation, pigtail endoscopic retrograde cholangiopancreatography stenting

\section{Introduction}

Biliary complications still remains as a significant cause of post-operative morbidity and mortality after liver transplantation with high incidence of about $15-45 \% \cdot{ }^{[1-3]}$ Most common complications which appear at early stage posttransplant patients are, biliary strictures, biliary leakage, and biliary stones. ${ }^{[4]}$ Endoscopic retrograde cholangiopancreatography (ERCP) plays an important role in the diagnosis and treatment of biliary and pancreatic diseases. ${ }^{[2,5]}$ The use of biliary stents was introduced in the late 1970s, and since then endoscopic and percutaneous insertion of biliary stents is used as a treatment option for patients. [6] Today; the application of endoscopic biliary complications after liver transplantation attempt to effective treatment and is preferred as a successful option. ${ }^{[4]}$ Different type and size and prosthetic material can be chosen while performing a biliary tract stenting. ${ }^{[7]}$ Although, plastic stents are less expensive and easier to remove or change, they have a shorter duration of patency and a higher risk of dislocation. ${ }^{[7,8]}$ Early complications of biliary stents are infection, pancreatitis, and bleeding; more late complications are stent dysfunction or migration, and much less frequently cholecystitis, duodenal perforation. ${ }^{[9]}$ Stent migration following this procedure rarely occurs in 5-10\% of the patients. Perforations due to a migrated ERCP stent is extremely rare. ${ }^{[10]}$ Mostly, migrated stents pass through the intestine and ejected with stool without any complication. ${ }^{[11,12]}$ Optimal treatment methods are still controversial in case of duodenal perforations. ${ }^{[13]}$ Because of the rarity of this complication, there is not a clear consensus on management guidelines and selection criteria for surgery or conservative management. ${ }^{[14]}$ Surgery is indicated in patients who is not successfully treated by endoscopic interventions, or have peritonitis with large amounts of collections following intestinal perforation. ${ }^{[12]}$ 


\section{Case Report}

Here, we present a 65-year-old female patient who underwent live donor-liver transplantation in 2019 due to liver failure by chronic Hepatitis-B infection. Thus, liver transplantation was planned for the patient as treatment. During the operation duct-to-duct anastomosis was performed over that catheter between greft's bile duct and the recipient's choledocus. The patient was discharged without complication on the post-operative $10^{\text {th }}$ day. She applied with abdominal pain 6 months later after transplantation. She had high White Blood Cell count, elevated Gamma Glutamyl Transferase, Alkaline Phosphatase and Bilirubin levels. Multi-Slice Computed Tomography performed and stricture was detected on bile duct anastomosis. Therefore, ERCP was performed and detected stricture at the anastomosis of bile tract, and dilatation on anterior and posterior sectors. Two endoscopic stents were placed in both sectors. After that procedure the patient had same complaint a few times more again, and ERCP was performed and endoscopic stent was applied as in previous procedures. The patient admitted to our clinic for ERCP stent revision 6 months later after the last ERCP stenting. ERCP process was performed as planned before, and previous placed stents removed and cholangiography scanned. Biliary tract dilatation on anterior and posterior section and stricture on anastomotic level was detected. 7 Fr 13 and $14 \mathrm{~cm}$ length new plastic stents were placed on distal of the stenosis on bile tract (Fig. 1). After that procedure, she was discharged without any disturbance. Her abdominal pain complains started again a few weeks after

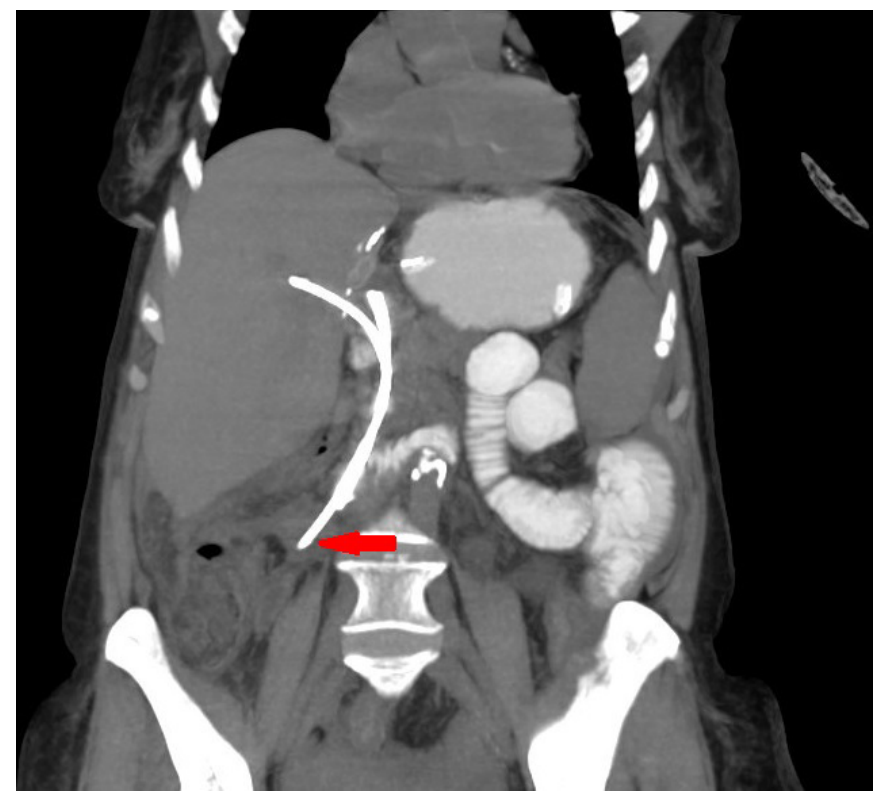

Figure 1. ERCP stent placed on bile tract. she discharged. She applied to another clinic and physical examination blood tests were obtained and infection parameters were high. Thereupon, the patient was admitted to our clinics. Exploratory laparotomy was planned as perihepatic and perisplenic and pelvic free liquid was seen on Computed Tomography (CT) scan (Fig. 2). Antibiotic treatments were started before the operation. We detected a perforation on the corner of the third portion of duodenum caused by endoscopic bile stent. And the tip of the stent was stuck in the meso of the transverse colon (Fig. 3). We removed the stent and explored the intestinal loops. Although the perforation occurred more than $24 \mathrm{~h}$ ago, the perforation site and duodenal wall were not inflamed as much as to prevent primary repair, and the perforation size was $<1 \mathrm{~cm}$. Therefore, we repaired the duodenum primarily by suturing double layer with $4 / 0$ prolene suture material and placed two drains both sides of perforation region. Enteral feeding was initiated on the post-operative $5^{\text {th }}$ day. Abdominal drains were extracted as the amount of drain's outcomes reduced. She was discharged after her antibiotic treatments were completed and infection parameters were regressed on the post-operative $20^{\text {th }}$ day.

\section{Discussion}

Although there are remarkable improvements in surgical techniques, biliary complications following liver transplant is still a significant reason for morbidity and mortality. ${ }^{[4]}$ Biliary complications after liver transplantation,

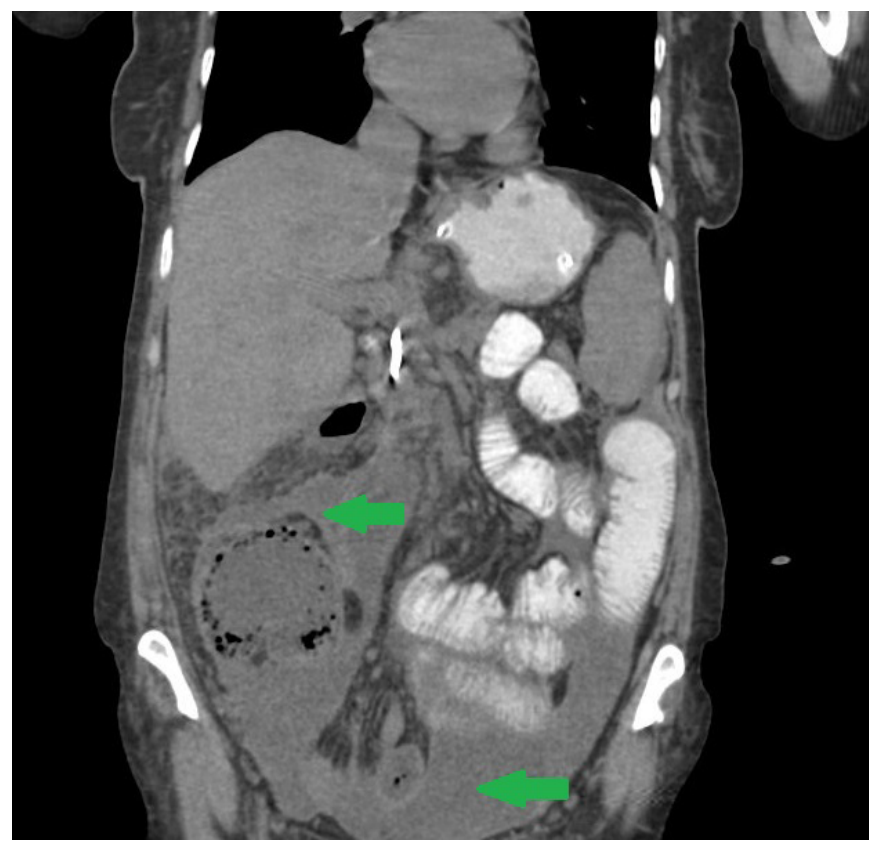

Figure 2. Intraabdominal free liquid determined on CT stan. 


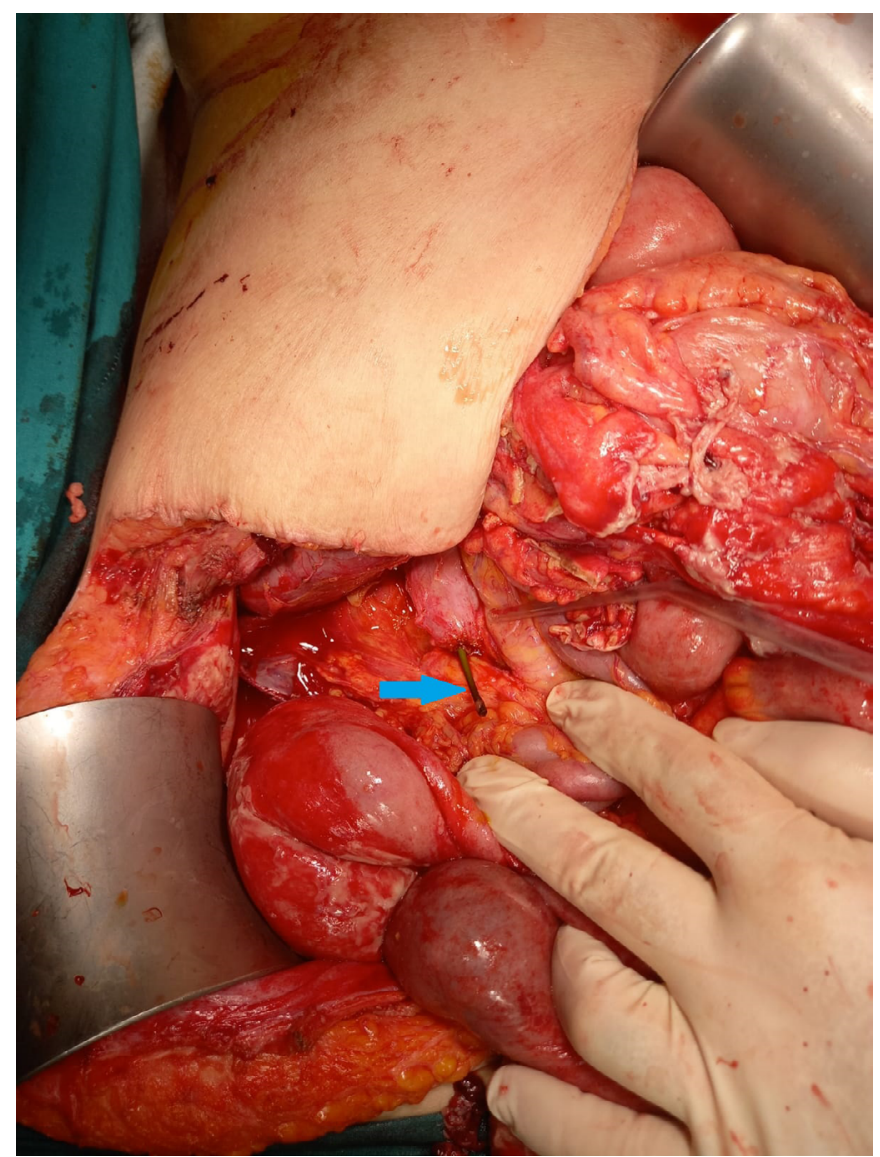

Figure 3. Duodenal perforation by ERCP stent.

include strictures, leaks, stones or debris, and sphincter of Oddi dysfunction. ${ }^{[1]}$ ERCP is a safe and effective way to diagnose and manage of biliary complications and avoids the need for surgical or percutaneous transhepatic approaches in the majority of cases. ${ }^{[15]}$ Biliary stents placing with ERCP, however, is not a procedure without complications. Complications specific to the stents include migration, occlusion, and intestinal perforation. [6] Biliary endoprosthesis can be classified into two categories by material type: Plastic and metallic stents. Plastic stents are easier to remove or to change and are less expensive but have a higher risk of clogging and dislocation. A big majority of those migrated stents are detected incidentally and pass through the intestine without any problems. Rarely, stents may stuck in the bowel and cause some unexpected complications. ${ }^{[7,8]}$ Featuring of the inserted stent, such as the type of material, length, flexibility, size, and the number of the stent may affect the risk of the migration. ${ }^{[6,10,16]}$ It is shown that longer stents $(\geq 13 \mathrm{~cm})$ are more likely to migrate distally in a retrospective study of more than 520 procedures. Bureau et al. are emphasized the length of the stent as a reason of migration in his cohort study. ${ }^{[17]}$ Migration of endoscopic biliary stents may occur either proximal or distal. ${ }^{[18]}$ Usually, longer stents are used in proximal strictures, and shorter stents are used in distal strictures. Therefore, shorter stents tended to migrate proximally and longer stents tended to migrate distally in benign biliary strictures. The number of stents is associated with decreased frequency of migration. Multiple stents tighten the bile tract and, and thus may prevent the migration. ${ }^{[18]}$ Katsinelos et al. reported that not any biliary stent migration was observed independently of size and length, if a pigtail stent was used. ${ }^{[7]}$ Intestinal wall weakness, previous surgeries, presence of diverticular disease, and herniations are important risk factors for perforation by a migrated biliary plastic stent. ${ }^{[8]}$ Beside the stent selection, stent migration may be related with poor insertion technique and inappropriate stent placement. ${ }^{[10]}$ Serious consequences of migrated stents such as intestinal perforation are about $<1 \%$. Most of those perforations occurs in the duodenum wall. ${ }^{[6,11]}$ Perforations which are occurred at the opposite wall of the duodenum by migrated biliary stent are rare and generally detected late. Abdominal and pelvic CT scan with oral contrast is the most sensitive and specific diagnostic way to evaluate for the presence of perforation. ${ }^{[12,14]}$ How to manage these duodenal perforations is not standardized because of the rarity of the cases. ${ }^{[13,19]}$ In case of intestinal perforation, depending on the patients' clinical situation, endoscopic approaches, or surgical interventions might be an appropriate choice. ${ }^{[8]}$ The main prognostic factor determining treatment efficacy is the time between perforation and treatment. Delayed diagnosis and treatment over $24 \mathrm{~h}$ are associated with a higher risk of mortality ${ }^{[13,19]}$ The surgical treatment choice depends on the size and localization of the perforation, the viability of the duodenal walls, and the degree of local contamination. ${ }^{[13]}$ The main purposes of the surgery are the control of sepsis by drainage of intra-abdominal collection and control of the source, and the repair of the perforation with/without diversion. ${ }^{[19]}$ Patients who is presented early with perforation $<1 \mathrm{~cm}$ are repaired primarily in one or two layers following debridement of devitalized tissue. ${ }^{[14]}$ The closure is performed transversely with or without the addition of an omental patch. Tube duodenostomy or other duodenal diversion techniques are preferred as a damage control procedure for high risk patients with delay in diagnosis or larger defects in duodenal wall. ${ }^{[13,14]}$ As a result, the choice of treatment should be individualized and depends on the mechanism of injury, the timing, location of the injury, and the clinical situation of the patient. ${ }^{[13]}$ 


\section{Conclusion}

ERCP is a potent minimally invasive treatment option for biliary tract problems, especially for bile tract stricture or bile leakage. Because of the high rate of the bile tract complications, liver transplant patients are potential candidate of ERCP procedures. Liver transplant patients have much more risk of infection due to immunosuppressive treatments. Therefore, less invasive approaches might lower the risk of infection on transplant patients. It has been shown that pigtail stent use in ERCP stenting may be useful to reduce the migration risk. Thickness and the number of the stent can avoid migration by sticking due to tightness. Also length of the stent is a determining reason for stent migration.

In conclusion, choice of ERCP stent type may be beneficial to minimize the need of repetitive ERCP and help to reduce risks of complications and the invasive procedures required for these complications. Since the inflammatory responses will be suppressed due to immunosuppression treatment in liver transplant patients and the rarity of the complication, migrated stent perforations generally detected late. Consequently in case of perforation on the intestinal lümen by a migrated ERCP stent, the main treatment should be surgical approach. The patient should be explored by laparotomy and explored the perforation area. The surgical treatment decision should be taken depending on the patient's clinical situation.

\section{Disclosures}

Informed Consent: Written informed consent was obtained from the patient for the publication of the case report and the accompanying images.

Peer-review: Externally peer-reviewed.

Conflict of Interest: None declared.

Authorship Contributions: Concept - S.U.; Design B.I.; Supervision S.U.; Materials B.M.K.; Data collection and/or processing B.M.K.; Analysis and/ or interpretation B.M.K.; Literature search - B.M.K.; Writing - B.M.K.; Critical review - S.Y.

\section{References}

1. Kochhar G, Parungao JM, Hanouneh IA, Parsi MA. Biliary complications following liver transplantation. World J Gastroenterol 2013;19:2841-6. [CrossRef]

2. Zhu G, Hu F, Wang C. Recent advances in prevention and management of endoscopic retrograde cholangiopancreatography-related duodenal perforation. Wideochir Inne Tech Maloinwazyjne 2021;16:19-29. [CrossRef]

3. Thethy S, Thomson BN, Pleass H, Wigmore SJ, Madhavan
$\mathrm{K}$, Akyol M, et al. Management of biliary tract complications after orthotopic liver transplantation. Clin Transplant 2004;18:647-53. [CrossRef]

4. Lee HW, Shah NH, Lee SK. An update on endoscopic management of post-liver transplant biliary complications. Clin Endosc 2017;50:451-63. [CrossRef]

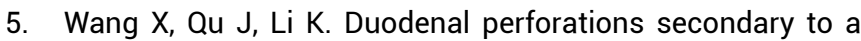
migrated biliary plastic stent successfully treated by endoscope: Case-report and review of the literature. BMC Gastroenterol 2020;20:149. [CrossRef]

6. Issa $\mathrm{H}$, Nahawi M, Bseiso B, Al-Salem A. Migration of a biliary stent causing duodenal perforation and biliary peritonitis. World J Gastrointest Endosc 2013;5:523-6. [CrossRef]

7. Katsinelos $P$, Kountouras J, Paroutoglou G, Chatzimavroudis G, Paikos D, Zavos C, et al. Migration of plastic biliary stents and endoscopic retrieval: An experience of three referral centers. Surg Laparosc Endosc Percutaneous Tech 2009;19:217-21.

8. Namdar T, Raffel AM, Topp SA, Namdar L, Alldinger I, Schmitt $M$, et al. Complications and treatment of migrated biliary endoprostheses: A review of the literature. World J Gastroenterol 2007;13:5397-9. [CrossRef]

9. Sohn SH, Park JH, Kim KH, Kim TN. Complications and management of forgotten long-term biliary stents. World J Gastroenterol 2017;23:622-8. [CrossRef]

10. Lo $\mathrm{CH}$, Chung S, Bohmer RD. A devastating complication: duodenal perforation due to biliary stent migration. Surg Laparosc Endosc Percutan Tech 2008;18:608-10. [CrossRef]

11. Topal U, Ülkü A, Sarıtaş AG, Akçam AT. A rare complication in a liver transplant patient: Meckel diverticulum perforation due to biliary stent. Int J Surg Case Rep 2018;53:35-8. [CrossRef]

12. Kumbhari V, Sinha A, Reddy A, Afghani E, Cotsalas D, Patel YA, et al. Algorithm for the management of ERCP-related perforations. Gastrointest Endosc 2016;83:934-43. [CrossRef]

13. Ansari D, Torén W, Lindberg S, Pyrhönen HS, Andersson R. Diagnosis and management of duodenal perforations: A narrative review. Scand J Gastroenterol 2019;54:939-44. [CrossRef]

14. Machado NO. Management of duodenal perforation post-endoscopic retrograde cholangiopancreatography. When and whom to operate and what factors determine the outcome? A review article. JOP 2012;13:18-25.

15. Thuluvath PJ, Pfau PR, Kimmey MB, Ginsberg GG. Biliary complications after liver transplantation: The role of endoscopy. Endoscopy 2005;37:857-63. [CrossRef]

16. Bharathi RS, Rao PP, Ghosh K. Intra-peritoneal duodenal perforation caused by delayed migration of endobiliary stent: A case report. Int J Surg. 2008;6:478-80. [CrossRef]

17. Bureau $M-A$, Gkolfakis $P$, Blero $D$, Pezzullo $M$, Devière J, Lemmers A. Lateral duodenal wall perforation due to plastic biliary stent migration: A case series of endoscopic closure. Endosc Int Open 2020;8:E573-7. [CrossRef]

18. Arhan $M$, Ödemiş $B$, Parlak E, Ertuğrul I, Başar Ö. Migration of biliary plastic stents: Experience of a tertiary center. Surg Endosc Other Interv Tech 2009;23:769-75. [CrossRef]

19. Preetha M, Chung YF, Chan WH, Ong HS, Chow PK, Wong $W K$, et al. Surgical management of endoscopic retrograde cholangiopancreatography related perforations. ANZ J Surg 2003;73:1011-4. [CrossRef] 